\title{
Principios y reglas del proceso oral y por audiencias: panorama general en el derecho comparado.
}

\section{Principles and rules of the oral process and by audiences: overview in comparative law.}

\author{
Ludwing Joseph Castro Castañeda ${ }^{1}$ \\ Jorge Zamudio Pulido² \\ RESUMEN
}

\begin{abstract}
El presente documento se encarga de realizar un abordaje panorámico en torno a los principios y reglas del proceso oral y por audiencias en el derecho procesal en el derecho comparado. Es de anticipar que, debido a la extensión del tema, este será delimitado en cuanto a países paradigmáticos (lo que la doctrina suele denominar "sistemas" o "familias jurídicas"), dependiendo el tipo de sistema adoptado. Así las cosas, el documento se divide en dos partes: la primera analiza países influyentes, o lo que Diego López llamaría "sitios de producción", mientras que la segunda parte, se concentra en el caso latinoamericano (lo que sería un ejemplo de un "sitio de recepción). Es decir, que tomaremos como centro de análisis la tradición occidental (civil law) y la tradición anglosajona (common law).
\end{abstract}

\footnotetext{
${ }^{1}$ Abogado, especialista en derecho administrativo y derecho de policía. Candidato a Magister en Derecho por la Universidad Externado de Colombia. Profesor investigador de la Facultad de Derecho de la Corporación Universitaria Uniciencia, sede Bogotá. Abogado consultor. Lcastro@deleonlegal.com.

2 Magister en Derechos Humanos por la Universidad Santo Tomás. Se ha desempeñado como docente universitario. Coordinador de Proyectos Jurídicos del Banco Agrario, Bogotá. Zarto28@gmail.com.
}

Recibido: 10 de febrero de 2019.Aprobado: 21 mayo de 2019. 


\title{
Palabras claves:
}

Familias jurídicas, derecho comparado, principios, reglas.

\begin{abstract}
ABSTRAC:
This document is responsible for making a panoramic approach to the principles and rules that operate in the procedural law regarding comparative law. It is to be anticipated that, due to the extension of the topic, this will be addressed only in terms of paradigmatic countries (what the doctrine usually denominates "systems" or "legal families") depending on the type of system adopted. Thus, the document is divided into two parts: the first analysis influential countries, or what Diego Lopez would call "production sites," while the second part focuses on the Colombian case (which would be an example of a "Reception site). is to say, that we will take as center of analysis the western tradition (civil law) and the Anglo-speaking tradition (common law).
\end{abstract}

\section{Keywords:}

Legal families, comparative law, principles, rules.

\section{Introducción a los sistemas jurídicos.}

Para indagar, de manera panorámica, sobre los principios y reglas que operan en el derecho procesal en cuanto al derecho comparado, y concretamente el principio oral y por audiencias, es necesario, en primer momento, comprender el origen de lo que la doctrina denomina las "familias o sistemas jurídicos". Existen dos grandes sistemas jurídicos, los occidentales, que lograron, de diversas formas, expandirse y/o imponerse 
a nivel global debido a múltiples circunstancias históricas, tales como el colonialismo, los procesos de evangelización, las cruzadas y en general los procesos de conquista. Esos dos sistemas son el Civil Law y el Common Law. El primero surge del derecho romano. Se alimenta del famoso Corpus luris del clásico jurista Justiniano, quien compiló las normas más importantes del derecho romano (las leyes, las constituciones imperiales, la jurisprudencia, los edictos, entre otras). Este sistema irradia en la mayoría de los países europeos-occidentales y, a partir del siglo XIX, en América Latina. La principal fuente del derecho es la ley, con fuerza vinculante, mientras que la jurisprudencia queda alojada en un lugar de mero criterio auxiliar. Ello supone que, el legislador es el principal actor dentro del sistema jurídico, y los jueces cumplen apenas un papel residual en el mismo. En la tradición francesa, en específico con la escuela de la Exégesis del Derecho, se fundan doctrinas como las del formalismo jurídico, las cuales permiten encuadrar a las culturas jurídicas dentro de una tradición de fuerte apego hacia el código (López, 2016).

En cambio, el sistema del Common Law no es la ley la principal fuente del derecho sino la jurisprudencia. El derecho entonces está constituido por el conjunto de precedentes, en especial de las altas cortes, donde establecen la forma en que se fallan los casos. El derecho es Law in action más que Law in book (códigos, textos legales).

Antes de entrar en materia, conviene advertir sobre la discusión semántica entre los conceptos de "principios" y "reglas". Por no ser el objetivo de este trabajo, apenas haremos alusión a la misma. Autores como Ronald Dworkin, Robert Alexy, Genaro Carrió, Gustavo Zagrebesly, entre otros (ver al respecto Berizonce, 2011) se han ocupado en numerosas ocasiones de ello. Algunos han sostenido que los principios, por regla general, se encuentran consignados en las cartas constitucionales, en específico en su parte dogmática, mientras que las reglas, aunque también en las constituciones, más en los códigos. Las primeras poseen una apertura semántica que las hace susceptibles de una fuerte carga ideológica. Lo que la profesora María Iglesias denomina como "conceptos esencialmente controvertidos". Más allá entonces de esta 
discusión, en lo que la doctrina parece estar de acuerdo es que los principios, leídos en sede constitucional, son la base de los ordenamientos jurídicos contemporáneos. A este fenómeno algunos autores han denominado "la constitucionalización del derecho", "nuevo derecho" o "neoconstitucionalismo".

Así las cosas, el principio de oralidad, en el caso alemán, los orígenes de este, se remontan al primer tercio del siglo XIX (el cual es copiado del modelo francés). Al respecto, afirman Pérez y Palomo (2009): "La oralidad fue considerada", en sus orígenes, "central no solo desde el punto de vista externo del proceso para su celeridad y transparencia, sino además desde lo interno para el logro más coherente de la incorporación y apreciación de la prueba para el logro de una sentencia lo más legitimada posible". Se aprecia entonces la relevancia no solo de contenidos "externos" como la celeridad y la transparencia sino también un elemento de legitimidad.

Mucho tiempo después, sería Robert Alexy quien haría este elemento central en las decisiones judiciales. Para así justificar porque los jueces, sin ser escogidos democráticamente, pueden llegar, en sede de argumentación, a legitimar sus decisiones. Ya no va a ser el elemento de legitimidad democrática el que haga válida una decisión sino (en el caso de los jueces) el elemento de legitimidad argumentativa.

Con el principio de oralidad, aparece el de publicidad. Así lo va a contemplar el artículo sexto del Convenio para la Protección de los Derechos Humanos y de las Libertades Fundamentales de la Unión Europea. Este principio es fundamental para que los ciudadanos puedan acceder al proceso judicial sin dilaciones o maniobras que perturben su conocimiento, a que su causa sea oída, equitativa, pública y dentro de un plazo razonable. El caso español también es sintomático al respecto. Desde al año 2000 España cuenta con una legislación civil renovada que dejó atrás la famosa Ley de Enjuiciamiento Civil de 1881. "Existía un importante grado de unanimidad para reconocer la existencia de serios problemas existentes bajo el modelo anterior a la LEC. Actual, que fueron afectando el desempeño de la Justicia civil la que, progresivamente, 
se fue distanciando de las necesidades de tutela de los justiciables. El diseño procesal basado fuertemente en la escritura era un problema. Concentrándonos en el juicio ordinario de mayor cuantía: excesiva rigidez formal, complejidad técnica, lentitud en su tramitación y elevado costo económico" Pérez y Palomo (2009, 4). Ahora bien si miramos la Constitución Española de 1978, su artículo 120 dispone que las actuaciones judiciales serán públicas, predominantemente orales y las Sentencias motivadas y en audiencia pública" ahí la importante reforma a la Ley de Enjuiciamiento Civil antes mencionada constitucionalizando la oralidad en los procesos.

Algunos autores sostienen que en el sistema occidental el ingreso de la oralidad a los procesos judiciales no ha sido sencilla a diferencia del sistema anglosajón, en el cual, la oralidad viene aunada a su esencia. Así lo expresa el profesor Oscar Guerrero $(2009,1064)$ al sostener, en el campo del derecho penal, "en el proceso continental la incorporación de celeridad y oralidad no resulta adecuada para una estructura burocrática jerarquizada..." (Guerrero, 2047). Tal argumento parece adquirir fuerza si se tiene en consideración que las familias del derecho occidental se formaron en la tradición de sistemas inquisitivos. Esto sin contar que para los "ciudadanos y las pequeñas y medianas empresas de los Estados miembros de la Unión Europea, los sistemas judiciales son demasiado costosos, lentos y complicados. El peso de los inconvenientes (obstáculos, costos, retrasos...) es inversamente proporcional a la cuantía del litigio (Vidal, 2015, 1).

Consideramos entonces, que no se puede hablar de un sistema oral puro, pues en realidad lo que perece existir son sistemas mixtos, dependiendo esta, en algunos casos, de la cuantía o a la pretensión. Por ejemplo, en cuanto a los procesos de escasa cuantía, en Alemania son simplificados cuando son inferiores a 600 euros. En este caso es posible el procedimiento escrito salvo que alguna de las partes solicite una fase oral. En el caso de Finlandia no depende de la cuantía sino de la pretensión; y será escritural siempre y cuando la resolución no exija fase oral y ninguna de las partes lo solicite. El caso de Suecia establece para demandas de menor cuantía en casos especiales, y que 
la cuantía no supere las 20.000 Coronas suecas. En Inglaterra y Gales el juez puede decidir realizar el procedimiento sin fase oral y basada en pruebas exclusivamente escritas. Existe sin embargo la posibilidad de que las partes puedan oponerse a lo anterior, sino lo hacen el procedimiento se dará de manera escritural. Irlanda del Norte posee una situación similar, pues en este tipo de procesos de menor cuantía, hasta 200 libras esterlinas, se da curso a la actuación con pruebas exclusivamente escritas siempre y cuando no se de oposición (Vidal, 2015, 3). Otras países como Bélgica se mueven en una dinámica distinta; el proceso "puede ser oral cuando se trata de asuntos urgentes o muy simples, en otro caso se fija una fecha para otra audiencia previamente a la cual se habrán realizado por escrito las alegaciones así como las conclusiones de las partes" (Vidal, 2015, 4).

\section{El Caso Latinoamericano}

En cuanto al caso latinoamericano la constitucionalización del derecho se dio desde la expedición de la Constitución de Brasil en 1988. Ingresando así, la región, en la denominada "fase madura" de uno de los fenómenos más importantes que ha sellado la evolución de la justicia en general, la "constitucionalización de las garantías" (Berizonce, 259, 2012). La CADH (Convención Americana de Derechos Humanos) por ejemplo, y en directa consonancia con lo establecido por la CEDH (Fundación Acción Pro -derechos Humanos). Consagrándose entonces un "núcleo duro" o "esencial" de principios para gobernar la administración de justicia civil, que vincula y obliga a todos los Estados miembros, y que resultan atinentes a la condición del juez, como imparcial e independiente; a las partes, a quienes se les ha de asegurar un acceso irrestricto a la jurisdicción y el derecho de defensa; y al procedimiento, el "fair trial" o debido proceso que ha de ser simple, claro y rápido, para ser oído "con las debidas garantías y dentro 
de un plazo razonable", lo que conlleva el dictado de un pronunciamiento debidamente fundado y justo. Se trata de las "garantías judiciales" (Berizonce, 2009, 259).

En el caso colombiano es de notable conocimiento que, nuestro sistema jurídico estuvo formado por la fuerte influencia de la familia Civil Law. La cultura jurídica colombiana, sostiene Diego López Medina (2016, 130), se construyó lentamente a lo largo de los siglos XIX y XX, con la recepción de tres trasplantes iusteóricos distintos: el "Code Napoleon y una tecnología formalista de la lectura del mismo predominante en el siglo XIX francés... el impacto que tuvo el trasplante de los métodos romanistas y privatistas alemanes del XIX... y tercero, ya bien entrado el siglo XX, la recepción, transformación y asimilación de la más influyente de todas las teorías positivistas europeas: la Teoría Pura del Derecho de Hans Kelsen".

Sin embargo, a partir de la expedición de la Constitución de 1991, la puesta en escena de la Corte Constitucional y múltiples desarrollos teóricos, todo este panorama se modifica trascendentalmente. Dando como resultado el surgimiento de lo que algunos autores como Manuel Cepeda denominaron el "nuevo constitucionalismo" o "neoconstitucionalismo".

De esta manera, en nuestro contexto, imperó un sistema reacio ante técnicas de oralidad, dándole preeminencia marcada al sistema escritural: donde el formalismo era el eje central del mismo. Al respecto, afirman autores frente al tema que, en el país la oralidad ha atravesado por múltiples etapas: en lo que tiene que ver con la historia más reciente: la entrada en vigencia de la ley 906 de 2004 es un fuerte referente; "fortaleciendo el principio acusatorio, entra en vigencia en 2005 y hace cambios en el proceso penal, buscando solucionar varios problemas evidenciados en este, a partir de la Constitución" (Osorio, Gaudenzi y otros, 5, 2012). Sin embargo, este pilar de la oralidad no entró en actividad en Colombia en el siglo XXI. Pues, según la Secretaría Permanente de la XIV Cumbre Judicial Iberoamericana, Colombia ha implementado parcialmente la oralidad en su ordenamiento desde 1948, y buena parte de la 
inspiración del Código de Procedimiento Civil estaba en la oralidad" (Osorio, Gaudenzi y otros, 5, 2012). Más adelante, "Con la implementación de la ley 1564 de 2012 que reemplaza el Código de Procedimiento Civil, la oralidad se expande a la jurisdicción civil, aunque previamente, con la ley 1395 de 2010, se había introducido una importante reforma al CPC, que incorporaba e implementaba un programa piloto de oralidad. La entrada en vigencia de la ley 1564 fue escalonada, finalizando el 1 de Enero de 2016, por lo que la implementación de la oralidad de manera generalizada es, en realidad, reciente" (Osorio, Gaudenzi y otros, 5, 2012).

\section{Conclusiones}

Con este trabajo se documentó de manera generalísima algunos de las principales normas generales de los ordenamientos jurídicos. Mostrándose que la tendencia suele moverse hacia sistemas impuros, es decir sistemas mixtos. Pues los modelos mixtos podrían adaptarse más a contextos diversos. De igual forma se mostró que en familias jurídicas de derecho civil la tendencia parece ser, en la mayoría de su historia, un sistema escritural. Mientras que en los países de derecho común la oralidad ha estado presente de manera predominante.

Teniendo en cuenta el análisis realizado de las escuelas o familias jurídicas civil law y el common law encontramos que los principales principios de la oralidad son: concentración, inmediación y publicidad, pues en ellas se concentra la unidad de actos, la apreciación directa de las pruebas, trasparencia, celeridad, economía procesal entre otros.

A contrario sensu de la oralidad tenemos amenazas importantes al sistema. La poca preparación de los intervinientes en la audiencia, dispersión de los actos procesales, mediación de la actuación y privacidad del contexto en el que debe 
desarrollarse la audiencia podrían llevar a la banalización del proceso oral y por audiencia.

Se requiere de unos intervinientes comprometidos con la causa, que la argumentación sea el eje principal del sistema y no que las decisiones se conviertan en superficiales y precipitadas, debe entonces primar una oralidad como principio que permita garantizar la tutela jurisdiccional efectiva en presencia de un juez que prepare el debate y le permita dominarlo. Además la oralidad compromete a las partes a facilitar la decisión del juez llevando las pruebas, acudiendo a las audiencias, haciendo argumentos pertinentes, fundados, claros, concretos y fáciles de entender por el que administra justicia.

\section{Referencias.}

Berizonce, Roberto. Nuevos principios procesales y su recepción en los ordenamientos jurídicos nacionales (influencias del Derecho Internacional de los Derechos Humanos). En: Anales No. 2. U.N.L.P. 2012. (Recuperado 15/02/2018. Disponible en: http://sedici.unlp.edu.ar/bitstream/handle/10915/27026/Documento completo.p df?sequence $=1$.

Carbonell, Miguel (2007). Teoría del neoconstitucionalismo. Ensayos escogidos. Trotta.

Osorio, Anna y Gaudenzi, Marianna y otros. La implementación de la oralidad: ¿una amenaza a la actividad probatoria? 2012. Universidad EAFIT, Medellín. Disponible

en: 
http://www.eafit.edu.co/investigacion/semilleros/Documents/ponencia semillero derecho procesal.pdf. Fecha de consulta: 21/02/2018.

Guerrero, Oscar (2006). El difícil encuentro entre el proceso penal anglosajón y el proceso penal continental. Biblioteca Jurídica Virtual de la UNAM (Recuperado en 15/02/2018. Disponible en: http://www.corteidh.or.cr/tablas/R08047-19.pdf.

López, Diego (2016). Teoría impura del Derecho. Transformación de la cultura jurídica latinoamericana. Legis, UNAL Universidad de los Andes.

Vidal, Begoña. Oralidad y escritura en el proceso declarativo europeo de escasa cuantía. Universidad de Valladolid. 2015. Recuperado 15/02/2018. Disponible en: http://biblioteca.cejamericas.org/handle/2015/2946?show=full. 